\title{
Malignant Transformation of Cerebellar Pleomorphic Xanthoastrocytoma: A Case Report
}

\author{
Oumar Coulibaly', Mahamadou Dama1, Oumar Diallo, \\ Quenum Kouassi Jean Marie Maurin Kisito², Li Gu1,3, Boubacar Sogoba1, \\ Moussa Denou' ${ }^{1}$, Sieleche Auxence Christ ${ }^{1}$, Youssouf Sogoba4, Mamadou Salia Diarra5, \\ Alpha Singuépiré1, Drissa Kanikomo4
}

${ }^{1}$ Hôpital du Mali, Bamako, Mali

${ }^{2}$ Unité de Neurochirurgie, Centre Hospitalier Départemental et Universitaire de Parakou, Parakou, Benin

${ }^{3}$ The First Affiliated Hospital of Medical School of Zhejiang University, Zhejiang, China

${ }^{4}$ Hôpital Gabriel Touré, Bamako, Mali

${ }^{5}$ Hôpital Mère-Enfant "Le Luxembourg”, Bamako, Mali

Email: coulibalynch1@gmail.com

How to cite this paper: Coulibaly, O., Dama, M., Diallo, O., Kisito, Q.K.J.M.M., Gu, L., Sogoba, B., Denou, M., Christ, S.A., Sogoba, Y., Diarra, M.S., Singuépiré, A. and Kanikomo, D. (2017) Malignant Transformation of Cerebellar Pleomorphic Xanthoastrocytoma: A Case Report. World Journal of Neuroscience, 7, 376-382.

https://doi.org/10.4236/wjns.2017.74029

Received: August 14, 2017

Accepted: October 27, 2017

Published: October 30, 2017

Copyright $\odot 2017$ by authors and Scientific Research Publishing Inc. This work is licensed under the Creative Commons Attribution International License (CC BY 4.0).

http://creativecommons.org/licenses/by/4.0/

\begin{abstract}
Pleomorphic xanthoastrocytoma (PXA) generally occurs in children and young adults and is classified as a low-grade astrocytic tumor with a potential favorable prognosis. But these data must be interpreted with much caution, because of some rapid progression or malignant transformation during the postoperative follow-up. We report herein a rare case of a cerebellar PXA manifested as a benign lesion at first time in a 39 year-old woman, but with malignant transformation two years later. In this paper, we discuss the clinical signs, radiological findings and the therapeutic data on the subject according to literature review.
\end{abstract}

\section{Keywords}

Pleomorphic Xanthoastrocytoma, Cerebellar, Malignant

\section{Introduction}

Pleomorphic xanthoastrocytoma (PXA), first described by Kepes et al. in 1979, is a rare neoplasm that accounts for less than $1 \%$ of all astrocytic tumors [1]. It had been considered as a low-grade astrocytic tumor with a relatively favorable prognosis compared to other astrocyte-derived tumors, and is classified as grade II in the World Health Organization (WHO) classification [1] [2]. But this situa- 
tion must be interpreted with much caution because of some rapid progression or some malignant transformation during the follow-up. Some PXAs can recur, become malignant or fateful for a patient [2] [3] [4] [5]. In this paper, we report a well-documented case of a malignant transformation of a cerebellar PXA with poor prognosis and we discuss the clinical course, surgical management and therapeutic findings on this special case.

\section{Case Report}

This 39 year-old woman, with no medical history, was admitted in our department for headache, vomiting and gait disturbance six months ago. Neurological examination only found a slight cerebellar ataxia with increased deep and superficial reflex. There was no deficit and no papilledema in ophtalmological test. A cranial CT scan showed a cystic midline isodense cerebellar lesion enhanced by contrast injection (Figure 1(a)). She underwent a midline suboccipital craniectomy procedure that allowed to a wholly gross total resection (Figure 1(b)). Histological examination of surgical specimen confirmed a diagnosis of PXA without anaplasia. She was discharged on the tenth postoperative day without any complications. A second postoperative CT scan 8 months later shown no evidence of recurrence (Figure 1(c)).

But, two years after the first surgery, she had been readmitted in emergency with the same clinical symptoms associated with vertigo and intermittent visual

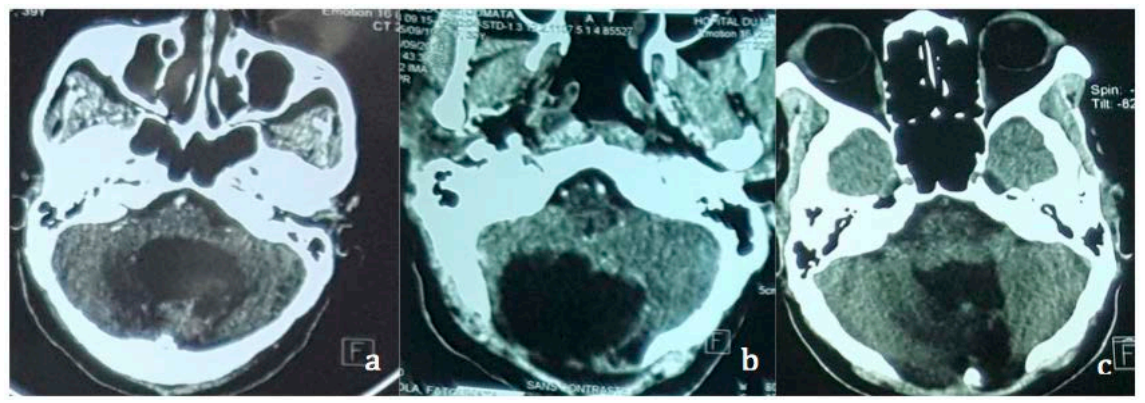

Figure 1. (a) Axial CT scan showing a cystic cerebellar lesion with contrast enhancement; (b) Immediate post operative CT scan showing a gross total resection of the mass; (c) No evidence of recurrence eight months after surgery.

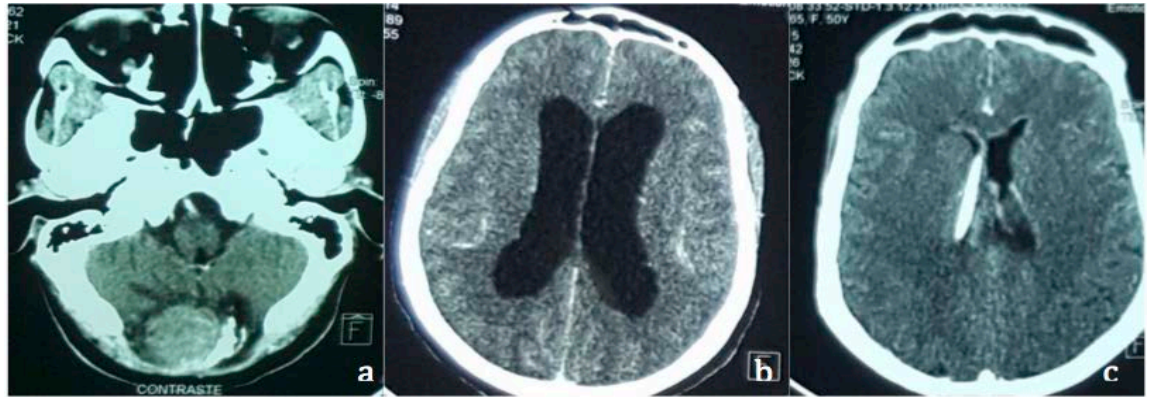

Figure 2. (a) Axial CT scan showing a recurrence of the tumor with solid components and central necrosis and (b) Tetraventricular hydrocephalus; (c) Ventriculoperitoneal shunt prior the second posterior fossa approach. 
lost. A CT scan revealed a recurrence of the posterior fossa mass, which became bigger than the first one, majority solid and associated to a tetraventricular hydrocephalus (Figure 2(b)). She had had ventriculoperitoneal shunt following a week later by a new posterior fossa approach. During this last operation, we found a grey-yellow median-density tumor with cystic cavities in posterior cranial fossa. We had some difficulties in differentiating the tumor from the normal cerebellar structures, so subtotal resection was performed. This time, histopathology examination demonstrated "a PXA with rapid progression or malignant transformation, astrocytoma WHO grade III" (Figure 2(b)). So, the patient was discharged with the advice for further radiotherapy. But two months later, she was received in severe cachexia and high nuchal rigidity. No radiotherapy had been done in our case. CT scan showed a recurrence of the mass that is large in size from all the posterior fossa to the supratentorial area. Due to the rapid progression of the tumor and the lack of therapeutic treatment options available to us, we decided to stop treatment after discussions with her family. She died three days later (Figure 2(c)).

\section{Discussion}

PXA is a low-grade astrocytoma that corresponds to a WHO grade II [6]. The majority of PXA cases occur in a supratentorial location within the temporal followed by parietal, frontal and occipital lobes [7] [8]. However, pure cerebellar PXA are very rare. Only 16 cases of cerebellar PXA had been related in the literature from which three had a malignant transformation (Table 1). The time from diagnosis to malignancy features was approximately 24 months in our case. Cerebellar PXA was more prevalent in females. Two-thirds of cerebellar PXAs occurred in adults and the average age at the time of diagnosis was 33 years. In contrast, supratentorial forms were observed in patients with a younger average age (21 - 26 years) [3] [4]. The main clinical signs in our case were headache, vomiting, and gait disturbance.
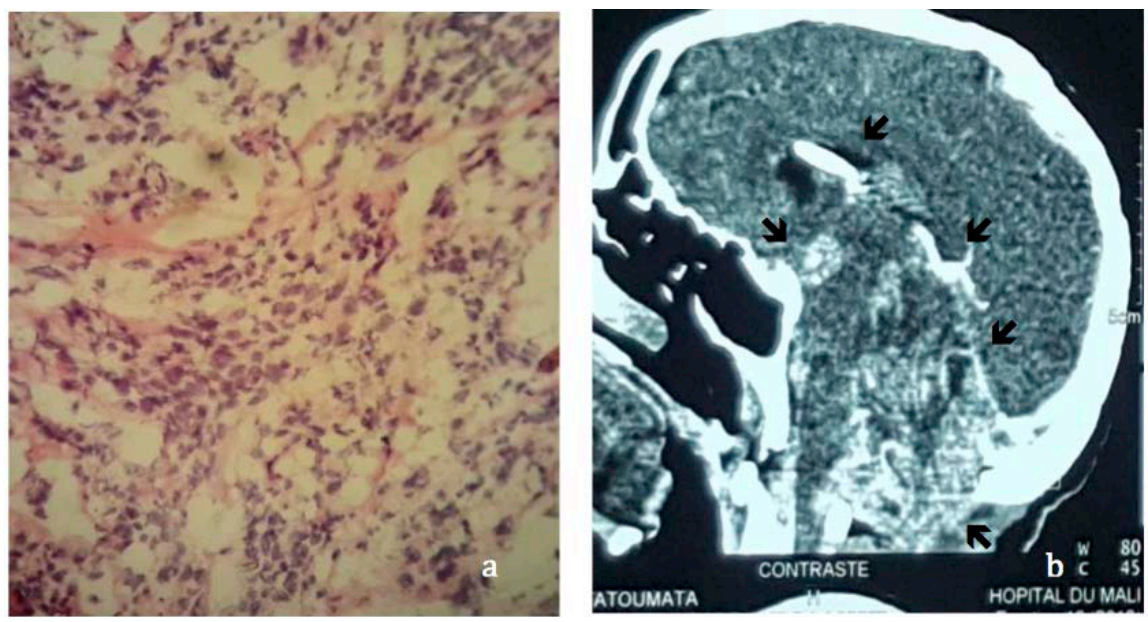

Figure 3. (a) Histopathological examination showed a PXA with foci of necrosis, vascular proliferation and high mitotic activity $(\times 10)$; (b) CT scan showing the second recurrence of the tumor from the posterior fossa to supratentorial area. 
Table 1. Cerebellar PXA cases reported in the literature [3].

\begin{tabular}{|c|c|c|c|c|c|c|c|}
\hline & Age & Sex & CT/MRI & Histology & Treatment & Recurrence & Follow-Up \\
\hline Chang, et al. & 4 & $\mathrm{~F}$ & Cyst & PXA-GG & $S+R X+C h$ & No & Well/144 m \\
\hline Evans, et al. & 60 & M & Solid & PXA-GG & $S+R X$ & No & Well/16 m \\
\hline Gil Gouvea, et al. & 40 & M & Solid & PXA-Pa & $S / S$ & $27 \mathrm{mo}$ & Well/27 m \\
\hline Glasser, et al. & 36 & $\mathrm{~F}$ & Solid & PXA & $S+R X / S$ & $\mathrm{C} / 16 \mathrm{y}-\mathrm{F}$ & NA \\
\hline Kumar, et al. & 15 & M & Cyst & PXA & S & NA & NA \\
\hline Lim, et al. & $3 \mathrm{~m}$ & $\mathrm{~F}$ & Solid & PXA & S & No & Well/13/16 m \\
\hline Lindboe, et al. & 27 & M & Cyst & PXA-GG & $S / S$ & $12 y$ & Well/11 m \\
\hline Naidich, et al. & 51 & $\mathrm{~F}$ & Solid & PXA-Pa & $\mathrm{B} / \mathrm{S}+\mathrm{RX}+\mathrm{S}$ & No & NA \\
\hline Perry, et al. & 24 & $\mathrm{~F}$ & Cyst & PXA-GG & S & No & Well/7 m \\
\hline Perry, et al. & 14 & $\mathrm{~F}$ & Cyst & PXA-GG & $\mathrm{S}+\mathrm{RX}+\mathrm{Ch} / \mathrm{S}$ & $12 \mathrm{mo}$ & Well/18 m \\
\hline Powell, et al. & 14 & $\mathrm{~F}$ & $\mathrm{Na}$ & PXA-GG & S & NA & NA \\
\hline Rosenberg, et al. & 68 & $\mathrm{M}$ & Solid & PXA & S & No & Well/5 m \\
\hline Saikali, et al. & 36 & $\mathrm{~F}$ & Solid & PXA-Olig & $S / S+R X+C h$ & Yes & Died at $3 y$ \\
\hline Wasdahl, et al. & 48 & $\mathrm{~F}$ & Solid & PXA-Pa & S & No & Well/18 m \\
\hline Hamlat, A. et al. & 58 & $\mathrm{~F}$ & Solid & PXA-Olig & $\mathrm{S} / \mathrm{S}+\mathrm{RX}+\mathrm{Ch}$ & $8 \mathrm{mo}$ & Died at $17.5 \mathrm{~m}$ \\
\hline Present case & 39 & $\mathrm{~F}$ & Solid & PXA & $S / S / S$ & 02 years & Died $26 \mathrm{~m} 3$ days \\
\hline
\end{tabular}

These signs are not specified to cerebellar PXA, but common for posterior fossa tumors (Figure 3(a) and Figure 3(b)). The radiologic features of this tumor have been well documented. All solid masses are enhanced with contrast material, and cyst-associated tumors are frequently observed in supratentorial locations [2] including a huge cyst with a mural nodule [9]. A higher incidence of solid enhancing tumor is observed in the posterior fossa ( 9 of the 14 cerebellar cases). However, imaging studies may reveal a well-circumscribed mass with a cystic component [4] [10] [11] [12], but a huge cyst with a mural nodule has not been found in cerebellar locations. Neuroradiologic studies are of little value in predicting the exact diagnosis before pathologic examination because there are no radiologic features pathognomonic of PXA [10] [11] [13].

The primary goal of PXA is gross total resection if possible and of course without neurological damage. But, in some cases, subtotal resection can be an option in case of recurrence or malignant transformation. PXA with malignant transformation had a relatively poor evolution despite the advanced therapeutic tools. All the three patients including ours died within three years of initial diagnosis, despite surgeries, chemotherapy or radiotherapy [3] [5]. However, in cases proven to be fatal, they usually have undergone transition to anaplastic astrocytoma or glioblastoma. Recurrences may show a histological pattern analogous to the original tumor, but increasing anaplasia may also be seen [2] [14] [15] [16]. The frequency of recurrence of PXA has been reported to be $30 \%$, and that of malignant transformation $10 \%-20 \%$ [16] [17]. In our case, after the 
second operation, histopathological examination was consistent with PXA with malignant transformation. This transformation of cerebellar PXA in our case is highly unusual; only three cases had been reported in the literature. This transformation had been done in a period of two years followed by rapid progression and fatal evolution. At present, the role of adjuvant radiotherapy and/or chemotherapy remains uncertain and controversial. However, adjuvant therapies can be administered to cases where recurrent tumors are shown to have metastasized or have aggressive extensions on MR images or new proliferative pathological markers are seen [18]. Postoperative radiotherapy is reserved for patients with anaplastic and recurrent tumors with malignant changes [19] [20] [21]. Chemotherapy has not been adequately studied [19]. The clinical course of patients with histologically malignant PXA was often more favorable and less precipitous than that of the patients with fibrillary astrocytomas that showed the same features [2]. Analysis of the published data reveals that the 5-year survival rate for the patients harboring "typical" PXA is approximately $80 \%$. None of the patients with "atypical" PXA have been reported to survive for more than 3 years with or without adjuvant therapies. Our patient had no adjuvant therapy after the second operation and the tumor made a rapid progression within all the posterior fossa with supratentorial extension during a very short time. We stopped our investigation and the patient died a few days later.

\section{Conclusion}

Cerebellar PXA with malignant transformation is rarely observed, with only 03 fatal cases including ours reported in the literature. The prognosis is very poor compared to supratentorial locations despite the use of adjuvant therapeutic tools after surgery. None of the patients suffering from PXA with malignant transformation has been reported to survive more than three years. As such, the initial diagnosis of this fatal progression of PXA must be established correctly.

\section{Acknowledgements}

We would like to thank Mrs. Barry Najah, Mr. Traoré Modibo and his team for their contributions.

\section{References}

[1] Kepes, J.J., Rubinstein, L.J. and Eng, L.F. (1979) Pleomorphic Xanthoastrocytoma: A Distinctive Meningo Cerebral Glioma of Young Subjects with Relatively Favorable Prognosis. A Study of 12 Cases. Cancer, 44, 1839-1852. https://doi.org/10.1002/1097-0142(197911)44:5<1839::AID-CNCR2820440543>3.0. CO;2-0

[2] Giannini, C., Scheithauer, B.W., Burger, P.C., et al. (1999) Pleomorphic Xanthoastrocytoma: What Do We Really Know About it? Cancer, 85, 2033-2045. https://doi.org/10.1002/(SICI)1097-0142(19990501)85:9<2033::AID-CNCR22>3.0.C $\underline{\mathrm{O} ; 2-\mathrm{Z}}$

[3] Hamlat, A., Le Strat, A., Guegan, Y., Ben-Hassel, M., Saikali, S. (2007) Cerebellar 
Pleomorphic Xanthoastrocytoma: Case Report and Literature Review. Surgical Neurology, 68, 89-94. https://doi.org/10.1016/j.surneu.2006.08.064

[4] Nitta, J., Tada, T., Kyoshima, K., Goto, T., Ishii, K., Hongo, K., Kobayashi, S. (2001) Atypical Pleomorphic Astrocytoma in the Pineal Gland: Case Report. Neurosurgery, 49, 1458-1460. https://doi.org/10.1097/00006123-200112000-00030

[5] Saikali, S., Le Strat, A., Heckly, A., Stock, N., Scarabin, J.M. and Hamlat, A. (2005) Multicentric Pleomorphic Xanthoastrocytoma in a Patient with Neurofibromatosis Type 1. Journal of Neurosurgery, 102, 376-381. https://doi.org/10.3171/jns.2005.102.2.0376

[6] Louis, D.N., Ohgaki, H., Wiestler, O.D., et al. (2007) Pathology and Genetics of Tumours of the Nervous System: WHO Classification of Tumours. World Health Organization, Geneve.

[7] Crespo-Rodríguez, A.M., Smirniotopoulos, J.G. and Rushing, E.J. (2007) MR and CT Imaging of 24 Pleomorphic Xanthoastrocytomas (PXA) and a Review of the Literature. Neuroradiology, 49, 307-315. https://doi.org/10.1007/s00234-006-0191-Z

[8] Gil-Gouveia, R., Cristino, N., Farias, J.P., Trindade, A., Ruivo, N.S. and Pimentel, J. (2004) Pleomorphic Xanthoastrocytoma of the Cerebellum: Illustrated Review. Acta Neurochirurgica, 146, 1241-1244. https://doi.org/10.1007/s00701-004-0366-5

[9] Arita, K., Kurisu, K., Tominaga, A., Sugiyama, K., Sumida, M. and Hirose, T. (2002) Intrasellar Pleomorphic Xanthoastrocytoma: Case Report. Neurosurgery, 51, 1079-1082.

[10] Nakamura, M., Chiba, K., Matsumoto, M., Ikeda, E. and Toyama, Y. (2006) Pleomorphic Xanthoastrocytoma of the Spinal Cord. Case Report. Journal of Neurosurgery Spine, 5, 72-75. https://doi.org/10.3171/spi.2006.5.1.72

[11] Zarate, J.O. and Sampaolesi, R. (1999) Pleomorphic Xanthoastrocytoma of the Retina. The American Journal of Surgical Pathology, 23, 79-81. https://doi.org/10.1097/00000478-199901000-00008

[12] Bayindir, C., Balak, N., Karasu, A. and Kasaroglu, D. (1997) Anaplastic Pleomorphic Xanthoastrocytoma. Child s Nervous System, 13, 50-56. https://doi.org/10.1007/s003810050040

[13] Kepes, J.J. (1993) Pleomorphic Xanthoastrocytoma: The Birth of a Diagnosis and a Concept. Brain Pathology, 3, 269-274. https://doi.org/10.1111/j.1750-3639.1993.tb00753.x

[14] Korshunov, A. and Golanov, A. (2001) Pleomorphic Xanthoastrocytomas: Immunohistochemistry, Grading and Clinico-Pathologic Correlations. An Analysis of 34 Cases from a Single Institute. Journal of Neuro-Oncology, 52, 63-72. https://doi.org/10.1023/A:1010648006319

[15] Nakajima, T., Kumabe, T., Shamoto, H., Watanabe, M., Suzuki, H. and Tominaga, T. (2006) Malignant Transformation of Pleomorphic Xanthoastrocytoma. Acta Neurochirurgica (Wien), 148, 67-71. https://doi.org/10.1007/s00701-005-0549-8

[16] MacCaulay, R.J., Jay, V., Hoffman, H.J. and Becker, L.E. (1993) Increased Mitotic Activity as a Negative Prognostic Indicator in Pleomorphic Xanthoastrocytoma: Case Report. Journal of Neurosurgery, 79, 761-768. https://doi.org/10.3171/jns.1993.79.5.0761

[17] Fouladi, M., Jenkins, J., Burger, P., Langston, J., Merchant, T., Heideman, R., Thompson, S., Sanford, A., Kun, L. and Gajjar, A. (2001) Pleomorphic Xanthoastrocytoma: Favorable Outcome after Complete Surgical Resection. Neuro-Oncology, 3, 184-192. https://doi.org/10.1093/neuonc/3.3.184

[18] Lim, S., Kim, J.H., Kim, S.A., et al. (2013) Prognostic Factors and Therapeutic Out- 
comes in 22 Patients with Pleomorphic Xanthoastrocytoma. Journal of Korean Neurosurgical Society, 53, 281-287. https://doi.org/10.3340/jkns.2013.53.5.281

[19] Chakrabarty, A., Mitchell, P., Bridges, L.R. and Franks, A.J. (1999) Malignant Transformation in Pleomorphic Xanthoastrocytoma-A Report of Two Cases. British Journal of Neurosurgery, 13, 516-519.

https://doi.org/10.1080/02688699908540631

[20] Tonn, J.C., Paulus, W., Warmuth-Metz, M., Schachenmayr, S.N. and Roosen, K. (1997) Pleomorphic Xanthoastrocytoma: Report of Six Cases with Special Consideration of Diagnostic and Therapeutic Pitfalls. Surgical Neurology, 47, 162-169.

[21] Charbel, F.T. (1998) Pleomorphic Xanthoastrocytoma with Malignant Progression. Surgical Neurology, 50, 385-386. 